\title{
A elaboração de projetos experimentais no ensino das Relações Públicas
}

\author{
Maria Francisca Magalhães Nogueira*
}

\section{Resumo}

Analisa suscintamente a experiência teórico-prática do curso de Relações Públicas (RP) da Faculdade de Comunicação e Biblioteconomia (Facomb) da Universidade Federal de Goiás (UFG), com a disciplina "Projetos Experimentais", ministrada no último ano do Curso. Estes Projetos têm como objetivo a melhoria da formação acadêmica-profissional dos alunos e são realizados em entidades de classe, sindicatos, instituições públicas, empresas privadas, entre outras. Apresenta a metodologia de orientação utilizada, o processo de execução e algumas experiências vividas em seu desenvolvimento, com predominância de temas institucionais, governamentais, comunitários e ecológicos. Conclui que os Projetos promovem o crescimento dos alunos, dos docentes e das próprias organizações onde são desenvolvidos. Palavras-chave: projetos experimentais em Relações Públicas, projetos experimentais e ensino, desenvolvimento de projetos experimentais.

\section{Introdução}

Os Projetos Experimentais do Curso de Comunicação Social são uma exigência legal prevista na Resolução $n^{\circ} 2$, de 1984, do extinto Conselho Federal de Educação (CFE), que fixa o Currículo Mínimo do Curso no Brasil. O Projeto compreende a produção de trabalho acadêmico relacionado com cada habilitação específica. No curso de Relações Públicas (RP), a forma mais adotada é o projeto prático, embora nada impeça, segundo a Resolução, que seja feita uma monografia. O Projeto pode ser produzido individualmente ou em equipes, dependendo do regimento de cada faculdade (França e Freitas, 1997, p.35-37).

* Relações Públicas, Mestre em Relações Públicas e Publicidade, profa. da Faculdade de Comunicação e Biblioteconomia da UFG.

Comun. Inf., v. 3, n. 2, p. 235-245, jul./dez. 2000 
Na Faculdade de Comunicação Social da Universidade Federal de Goiás (UFG), o Projeto Experimental é uma disciplina ministrada noúltimo ano do curso de Comunicação Social, com carga horária de 320 horas. No caso específico do Curso de RP constitui-se no planejamento de programas de Relações Públicas e sua realização em laboratórios da própria escola, além de outras formas, a critério da Coordenação do Curso (Resolução 196 do CCEP da UFG, Art. $8^{\circ}$. P. 3).

O Projeto Experimental do curso de Relações Públicas da UFG é uma experiência teórico-prática, realizada pelo aluno, sob a orientação de um professor. Os projetos são desenvolvidos essencialmente em Goiânia e, excepcionalmente, em cidades do interior do Estado de Goiás. Esses trabalhos têm possibilitado aos alunos o exercício do ato de planejar, organizar e executar projetos práticos de Relações Públicas em uma empresa real, abrir mercado de trabalho e aproximar universidade da comunidade. Os projetos desenvolvidos abrangem temas institucionais, governamentais, comunitários, ecológicos e outros. São desenvolvidos em entidades de classe, sindicatos, instituições públicas, empresas privadas, organizações sem fins lucrativos etc.

\section{A orientação do planejamento, organização e execução do Projeto Experimental}

Para o desenvolvimento eficaz dos projetos exigiram-se critérios preestabelecidos pelo conjunto de professores das disciplinas do curso de RP. Algumas etapas são obedecidas ao longo de todo o percurso, a fim de que os resultados sejam alcançados.

Os alunos agrupam-se em equipes, em torno de cinco pessoas, escolhem o tema e o tipo de organização onde pretendem desenvolver seu projeto. Nos primeiros dias de aula dessa disciplina, os professores do Curso de RP reúnem-se e discutem as proposições dos alunos. Posteriormente a essas discussões, os professores selecionam os grupos de orientandos pela proximidade com seu campo de estudo e experiência profissional.

\subsection{A formação das equipes, a escolha do tema e do local} de trabalho e a elaboração da proposta para o cliente

O primeiror contato do professor com seu grupo de orientandos serve para delimitar o papel do orientador e para estabelecer contrato psicológico entre as partes. O contrato psicológico tem como objetivo

Comun. Inf., v. 3, n. 2, p. 235-245, jul./dez. 2000 
fazer com que professor e aluno discutam as expectativas de ambos quanto ao trabalho a ser realizado. Como destaca Porto Simões (1997, p. 164), a função do contrato psicológico:

"Constitui a etapa preliminar e necessária para ajuste da linguagem, das atribuições e das responsabilidades - das normas básicas do convívio profissional - em face do objetivo comum. Compatibilizam-se então as condições para as trocas de idéias e para as tomadas de decisão, prevenindo-se mal-entendidos e frustrações futuras. Isso legitima as decisões a serem tomadas e minimiza a probabilidade de ocorrência de conflitos".

Aproveita-se esse momento para ressaltar pontos positivos do trabalho em equipe e suas dificuldades. Acontece de a equipe já vir sendo formada em anos anteriores e chegar à $4^{a}$ série já coesa, com proposta alinhavada e com a empresa previamente acertada. Nãoé comum, mas pode acontecer, de que quando tudo parece estar dando muito certo, um estudante ou o próprio grupo descobre que não se identifica com o grupo, o tema ou com a instituição, então, recomeça-se do zero.

Mesmo a equipe já estando com proposições previamente elaboradas, elas são revisadas pelo orientador. Os alunos são orientados a apresentar suas idéias com argumentações convincentes para, logo de início, obterem credibilidade junto à instituição. Essa atitude pode fazer com que a equipe não chegue ao cliente desarticulada, sem conhecimento mínimo do tema e da empresa; logo, não gerando mal entendidos, como a suposta perda de tempo para o cliente e a impressão negativa do grupo.

A proposta é apresentada à empresa pela equipe de alunos e, se aprovada, dá-se continuidade ao processo de planejamento do trabalho. É importante que a empresa assuma por escrito, geralmente na proposta, o compromisso com o desenvolvimento do trabalho.

Para a maioria dos grupos, as propostas têm se constituído em uma estratégia para conseguir o compromisso da organização quanto à execução do trabalho. Na proposta deixa-se claro os objetivos do projeto de RP, os benefícios que a instituição poderá obter. Essa primeira realização é um bom exercício de argumentação para os alunos, porque nela terão que convencer a empresa da qualidade e utilidade de seu trabalho. Um roteiro básico de proposta, com justificativa, objetivos, público-alvo, estratégias de ação, recursos estimados e delimitação de responsabilidades, tem ajudado os alunos a garantirem espaço de ação nas instituições.

Comun. Inf., v. 3, n. 2, p. 235-245, jul./dez. 2000 
Os alunos não tendo conhecimento preliminar mínimo dispensável da organização, este é realizado paralelamente à elaboração da proposta, a fim de que ela seja coerente com a realidade interna e externa da instituição. Para isso, as equipes são orientadas a consultar publicações especializadas ou da própria empresa e matérias veiculadas na imprensa, além de promoverem visitas à organização e contatarem os que a conhecem ou nela trabalham.

Nesse momento, observa-se o crescimento e amadurecimento intelectual obtido pelo aluno durante os anos anteriores. Para auxiliar a suprir certas lacunas, o professor sugere que os alunos consultem o que estudaram, pensem em proposições criativas, ponderadas e viáveis a fim de que tenham chances de serem executadas. $\mathrm{O}$ orientador tenta ampliar os horizontes da equipe mostrando as amplas possibilidades que o tema selecionado pode oferecer em oportunidade de enriquecimento. Como diz França e Freitas $(1997,101)$, dessa prática pode fluir "pesquisa bem fundamentada, diagnósticos profundos, projetos de grande alcance e não apenas proposta de melhoria da mídia existente ou criação de novos veículos, como acontece habitualmente".

Essa experiência tem demonstrado que quando o grupo começa a ser constituído na $3^{\circ}$ série do curso de Relações Públicas, com a intenção de desenvolver o Projeto Experimental juntos, e ainda, aproveita as disciplinas de Metodologia de Pesquisa, a equipe ganha em tempo e qualidade do projeto. Ao longo do curso, os alunos visitam organizações, fazem pesquisa bibliográfica visando conhecimento mais aprofundado de seu objeto de interesse, preparam-se para apresentação pública dos trabalhos. Desde o primeiro ano do curso, todos os alunos do Curso de RP assistem à apresentação final dos Projetos Experimentais - evento realizado a cada final de ano. Nem sempre acontece como seria ideal, de serem cumpridas todas as etapas necessárias ao bom desenvolvimento do Projeto Experimental.

\subsection{A Pesquisa, o diagnóstico, o projeto de RP \\ e o relatório final}

\section{- A elaboração da pesquisa}

A proposta já aceita, os alunos começam o contato direto com a instituição. Nessa etapa, o conhecimento prévio da empresa é im-

Comun. Inf., v. 3, n. 2, p. 235-245, jul./dez. 2000 
portantíssimo para que tenha efeito prático - o aluno demonstrará que conhece o que está fazendo, domina a linguagem do negócio, não perturba o tempo e o cronograma de trabalho do cliente, que geralmente é um executivo autorizado responsável por essa experiência dentro da empresa (França e Freitas, 1997).

A investigação é importante e oferece resultados aprofundados para a elaboração do diagnóstico. Dependendo do projeto e de suas necessidades específicas, o aluno pode utilizar-se de vários tipos de pesquisa: a auditoria de opinião, a auditoria de comunicação, a auditoria da cultura empresarial e a pesquisa institucional.

$\mathrm{Na}$ auditoria de opinião pode-se conhecer, por meio de entrevistas programadas, o conceito e a opinião que os públicos têm da organização, selecionando-se representantes de áreas vitais, dentro e fora da empresa. Na auditoria de comunicação pode-se avaliar todo o sistema de comunicação e de suas práticas tanto em nível micro como macro. Neste tipo de investigação obtem-se dados das áreas de comunicação existente - de sua estrutura de funcionamento, do perfil de seus coordenadores e colaboradores, das atividades desenvolvidas e das mídias utilizadas. $\mathrm{Na}$ auditoria da cultura empresarial pode-se conhecer a história da organização, as normas e os procedimentos utilizados. Na pesquisa institucional obtem-se informações a respeito da constituição da organização e de suas operações. Investiga-se como a instituição está estruturada, serviços que presta, produtos que vende (França e Freitas, 1997).

Após a investigação, faz-se o exame da situação. Aqui, o aluno deverá ter paciência para fazer uma correta interpretação visando um diagnóstico coerente. Os projetos de Relações Públicas não podem dar soluções antecipadas para temas não estudados, problemas não levantados, porque isto pode conduzir a projetos ingênuos e fora do contexto organizacional.

O Projeto de pesquisa não pode ser desprezado, pois ele será o elemento-base para uma boa avaliação da situação de comunicação em foco, ou mesmo, de todo o sistema de comunicação.

\subsection{A elaboração do diagnóstico}

O diagnóstico consiste em dizer qual o estado real da comunicação. Quando o diagnóstico é elaborado sem profundidade vêem-se propostas de comunicação tradicionais, que não visualizam a institui-

Comun. Inf., v. 3, n. 2, p. 235-245, jul./dez. 2000 
ção de forma global, conseqüentemente, acarretando estratégias esporádicas, sazonais e sem o sentido da continuidade e integração tão importante para a visão integrada dos relacionamentos entre organização e seus públicos.

Acredita-se que o diagnóstico tem sido uma das práticas mais dificeis para os alunos. Em algumas situações, eles estão de posse dos dados da pesquisa, mas não conseguem interpretá-los e correlacioná-los. À parte disto, o projeto têm constituído-se uma experiência prática importante para os alunos do Curso de RP.

Observa-se que os alunos chegam ao $4^{\mathrm{a}}$ ano com muita vontade de desenvolver uma experiência prática e já querem começar pela execução propriamente dita. Além disso, deparam-se com necessidades emergênciais de comunicação das organizações e com a ansiedade de dirigentes em obter resultados a curtíssimo prazo com o trabalho. É necessário grande esforço de argumentação do orientador para que o aluno se convença e dialogue com a empresa a respeito da importância de cumprir as etapas anteriores, especialmente um diagnóstico bem fundamentado com pesquisa.

Os orientadores mostram aos alunos as várias e distintas possibilidades de apresentação escrita de um projeto de RP, porém sempre lhes dão um roteiro básico. Este roteiro pode ser constituído de: título, introdução, justificativa, diagnóstico, objetivos gerais e específicos, público alvo, estratégias a serem seguidas, estimativa de custos, cronograma de execução, responsabilidades das partes envolvidas, formas de avaliação, conclusão, anexos e bibliografia.

\section{$2.4 O$ relatório final}

Ao final, os alunos elaboram um relatório, no qual apresentam os resultados das experiências vivenciadas ao longo de todo o ano.

\section{A importância dos projetos de Relações Públicas para a comunidade}

A universidade tem estado em constante debate e cobra-se dela maior aproximação da sociedade que a custeia, ensino de qualidade, pesquisa que dê respostas a muitos questionamentos e serviços à comunidade. Os Projetos Experimentais têm-se constituído em uma das oportunidades para a universidade dar respostas aos reclames da so-

Comun. Inf., v. 3, n. 2, p. 235-245, jul./dez. 2000 
ciedade. Muitos dos trabalhos desenvolvidos nessa disciplina do Curso de Relações Públicas da UFG têm fomentado o debate em torno de questões fundamentais, realizando pesquisas de interesse social e prestado serviços à comunidade.

Os trabalhos dessa disciplina têm sido um lugar importante para o debate pluralista das idéias entre alunos, professores e instituições onde são desenvolvidas essas experiências. Os projetos também estreitam o relacionamento entre professores, alunos e mercado de trabalho e, inclusive, têm propiciado perspectiva profissional para os estudantes. As equipes, mesmo que formadas por alunos com características e objetivos diferentes, se não divergentes, se unem em torno de uma missão comum, e por meio dessa vivência obtêm uma visão global e não parcial da comunicação das instituições.

Os projetos têm ajudado sindicatos, associações, empresas públicas e privadas e outras a buscarem qualidade em suas ações de comunicação com seus públicos interno e externo, a implementar ações que agreguem o público interno em torno da identidade global da instituição; propiciado alterar, criar e implementar sistemas de comunicação apropriados à realidade de cada uma das organizações e, em muitos casos, têm colaborado para tornar mais fortes e visíveis aspectos positivos da identidade das instituições em estudo.

\section{Algumas das experiências realizadas pelo Curso de Relações Públicas}

Os Projetos Experimentais têm proporcionado a professores e alunos vivências as mais diversas. Ao longo dos anos, eles têm sofrido alterações metodológicas, porém sua espinha dorsal continua firme no sentido de mostrar ao aluno que a comunicação das organizações deve ser concebida de forma global e não parcial, podendo assim demonstrar às empresas a importância de construir-se filosofia e políticas estratégicas de comunicação viáveis e com compromisso com resultados.

Foram muitas as experiências até agora desenvolvidas. Vamos aqui exemplificar algumas delas para que se tenha uma idéia de sua oportunidade e relevância:

- O projeto experimental "Desenvolvendo o Turismo na Cidade de Corumbá", executado no ano de 1997, pelas as alunas Pa-

Comun. Inf., v. 3, n. 2, p. 235-245, jul./dez. 2000 
trícia Novaes do Amaral, Paula Gardênia Dias Fernandes, Cibele Silva Medina, Simone Freire Feranandes, Raquel Salvato e Flávia Savastano, sob a orientação do professor Júlio Afonso Sá de Pinho Neto, foi premiado pela Associação Brasileira de Relações Públicas de São Paulo, que anualmente premia os melhores trabalhos desenvolvidos pelos cursos de Relações Públicas em todo o país. O projeto, desenvolvido para a prefeitura de Corumbá de Goiás, obteve destaque na categoria "projeto experimental".

Esse projeto preocupou-se, antes de qualquer outra medida, em ouvir a população da cidade e conhecer suas expectativas em relação à atividade na região. Toda uma gama de estratégias como palestras para empresários e vereadores, teatro de fantoches, gibis e gincanas com alunos das escolas do ensino fundamental e médio, criação e distribuição do guia de turismo mirim, montagem de pontos de informação turística, cursos de arte e artesanato para incentivar o comércio voltado para o turismo, dentre outras, foram orientadas sob o princípio de que todo esforço para desenvolver o turismo no município deveria ter como objetivo maior a melhoria da qualidade de vida dos cidadãos. As atividades em que estes poderiam contribuir de forma mais concreta e imediata deveriam ser privilegiadas. Tal trabalho, para melhor atingir essa finalidade, precisou conhecer os problemas, anseios e perspectivas dos municípios, para em seguida montar as estratégias de ação. Somente assim obteve-se a participação conjunta e efetiva da população da cidade, pois esta sentiu-se perfeitamente integrada nas atividades e co-autora do projeto.

O trabalho atingiu os objetivos a que se propôs, principalmente por não ter sido desenvolvido pela mera ótica da divulgação publicitária; antes se preocupou em diagnosticar os problemas existentes na área do turismo, conhecendo a opinião e coletando as sugestões da própria população corumbaense. Esta é a marca maior de um trabalho de Relações Públicas: ouvir e trabalhar em conjunto com os diversos segmentos sociais, elevando-os ao status de verdadeiros públicos, educando-os para o exercício da cidadania e para atuarem como partícipes de todo processo de trabalho.

- O projeto experimental "Atendimento, Comunicação e Comunidade" foi desenvolvido no ano de 1999 em Goiânia, no PREN-

Comun. Inf., v. 3, n. 2, p. 235-245, jul./dez. 2000 
DAS Supermercado, pelas alunas Andréa Cândido S. Pacheco, Anta Eurídice, Maria Janne D. Alves e Simone Alves dos Santos, sob a orientação da professora Lindsay Borges. As alunas foram motivadas a realizar esse projeto pelo fato de a empresa estar interessada em participar dos interesses da comunidade e promover atendimento personalizado e de qualidade.

O trabalho teve como objetivo voltar-se para questões relativas à qualidade dos serviços prestados pelo supermercado. Para isso, realizou-se um planejamento estratégico, visando estabelecer levantamentos e ações mais globais. Dentre essas ações, destacam-se o diagnóstico feito por meio de pesquisa de opinião junto a clientes e funcionários, a pesquisa sobre a concorrência e outras. Posteriormente, foi realizada campanha de RP, incluindo várias outras ações e eventos, peças de divulgação, confraternização de Natal, Dia da Criança e outras. A equipe recebeu declaração de satisfação do PRENDAS, atestando os benefícios obtidos com o projeto de RP.

- O projeto "Integrar é Unir para Melhor Servir", realizado na Comunidade Espírita Esperança e Fraternidade, no ano de 2000, pela aluna Suzy Meiry Silva, sob a orientação da professora Maria Francisca Magalhães Nogueira, centrou-se na comunicação interna. Esse projeto teve como objetivo principal desenvolver, aperfeiçoar e fortalecer a integração entre todos os trabalhos realizados pela Comunidade Espírita. Foram criadas e implementadas estratégias para conhecer a estrutura de funcionamento, os trabalhos por eles realizados, a filosofia e as políticas de comunicação em curso pela importância destas no eficaz planejamento do trabalho de Relações Públicas, ainda mais tratando-se de instituição religiosa com cultura e características muito próprias.

As ações concentraram-se nas formas de comunicação burocrática e interna. Foram selecionadas ações e mídias de comunicação para alcançar a integração interna. Dentre as escolhidas, foi criado um jornal mural com a participação do público interno, planejados e reorganizados almoços beneficentes, realizadas confraternizações e criadas peças de comunicação para divulgação dos trabalhos do Centro Espírita.

Comun. Inf., v. 3, n. 2, p. 235-245, jul./dez. 2000 
Os resultados com este projeto levaram a implementação de mudanças significativas no relacionamento interno, facilitando a integração entre todos os trabalhos desenvolvidos pelo Centro Espirita e, ainda, motivou-o à criação de um setor específico de comunicação.

\section{Conclusão}

O ingresso no mercado de trabalho sempre foi uma questão dificil para o recém-formado. $O$ estudante enfrenta um mercado cada vez mais exigente, sem tempo para oferecer-lhe um programa de treinamento e, nesse sentido, o projeto experimental tem sido uma experiência importante para o estudante do curso de Relações Públicas. Os alunos do último ano do curso, com seus projetos, têm divulgado a Universidade, a Faculdade de Comunicação e Biblioteconomia, as atividades e o curso de RP, e têm aberto mercado de trabalho e demonstrado a importância do planejamento e administração da comunicação para a eficácia dos relacionamentos internos e externos à organização.

Muitos são os pontos positivos apontados pelas empresas com a atuação dos alunos: aprimoramento dos relacionamentos com seus públicos de interesse, promoção de mudanças substanciais em sua forma de conceber e divulgar a imagem institucional da empresa, e delimitação da comunicação planejada e contínua, como parte integrante de seu organograma e cronograma de trabalho.

\section{Abstract}

This study briefly analyses a theoretical and pratical experiment conducted at the Public Relations Course at Faculdade de Comunicação e Biblioteconomia (Facomb) from Universidade Federal de Goiás, concerning the subject "Projetos Experimentais", which is taught in the last year of the course. These projects aim at improving the students academic and professional development and they are carried out in class entities, syndicates, public institutions, private enterprises, among others. The methodology used to carry out the projects, the process involved in its accomplishment and some experiences which came up with its realization are also shown. The main themes of the projects were institutional, governmental, community and ecological. The results show that these projects promote students growth, teachers and also the growth of the organizations where these projects are carried out.

Keywords: experimental projects in Public Relations, experimental projects and teaching, conduct of experimental projects.

Comun. Inf., v. 3, n. 2, p. 235-245, jul./dez. 2000 


\section{Referências}

ALVES, Maria Janne Dias; PACHECO, Andréa Cândida Silva; WEBBA, Anta Eurídice Baptista; SANTOS, Simone Alves dos. Atendimento, comunicação e comunidade. Goiânia, 1999. Relatório do projeto experimental realizado no PRENDAS Supermercado.

BORDENAVE, Juan Diaz; CARVALHO, Horácio Martins de. Comunicação e Planejamento. Rio de Janeiro: Paz e Terra, 1979.

EVANGELISTA, Marcos Fernando. Planejamento de relações públicas. Rio de Janeiro:Tecnoprint, 1983.

FORTES, Waldyr Gutierrez. Pesquisa institucional: diagnóstico organizacional para Relações Públicas. São Paulo: [s.n.], 1990.

FREITAS, Sidnéia G.; FRANÇA, Fábio. Manual da qualidade em projetos de comunicação. São Paulo: Pioneira, 1997.

KUNSCH, Margarida Maria Krohling. Planejamento de Relações Públicas na comunicação integrada. São Paulo: Summus, 1986.

LOPES, Maria Immacolata Vassalo. Pesquisa em comunicação: formulação de um modelo metodológico. São Paulo: Loyola, 1990.

SEVERINO, Antônio Joaquim. Metodologia do trabalho científico. São Paulo: Cortez, 1993.

SIMÕES, Roberto Porto. Relações Públicas: função política. São Paulo: Summus, 1995

SILVA, Suzy Meiry. Integrar é unir para melhor servir. 2000. Relatório do Projeto Experimental. Trabalho acadêmico.

UNIVERSIDADE FEDERAL DE GOIÁS. Conselho Federal de Ensino e Pesquisa. Resolução nº 196 de 1984. Fixa o currículo do curso de graduação em Direito. Goiânia, 1984.

Comun. Inf., v. 3, n. 2, p. 235-245, jul./dez. 2000 